\title{
El coro satírico y su función en las tramas satíricas esquileas. Notas sobre la gestualidad del coro y el rol actancial de Sileno en Arrastradores de redes
}

\author{
Satyric Chorus and its function in Aeschylean Satyric mŷthoi. Some notes on choral gestures and Silenus' actant role \\ in Nethaulers. \\ Guillermo De Santis \\ Centro de Investigaciones y Estudios sobre Cultura y Sociedad (CIECS), \\ Universidad Nacional de Córdoba / CONICET, Argentina \\ guillermode.santis@gmail.com \\ (iD) http://orcid.org/0000-0003-3545-7855
}

\section{Resumen:}

El presente artículo intenta mostrar algunos aspectos del rol dramático y la función escénica del coro en la producción satírica de Esquilo, específicamente en el Fr. 47 a R, versos 821-832. La hipótesis del trabajo sostiene que este canto coral debe entenderse en dependencia de la anterior canción de Sileno, versos 802-820, par estrófico con el cual muestra una evidente relación temática de complementariedad. Desde el punto de vista escénico, la imbricación del Coro en la trama satírica es directa, al punto que asume un rol actancial que posibilita un esquema de integración y separación de Sileno en el acción coral alternando como corifeo y actor. La interacción entre ambos pasajes líricos no solo se constataría en la temática y en la lengua sino también en la gestualidad del coro, respecto de lo cual se propone entender algunos indicadores gestuales que permiten organizar la escena.

Palabras Clave: Coro Satírico, Gestualidad, Función escénica, mythos satírico, Sileno.

\section{ABstract:}

The aim of this paper is to make visible some aspects of the dramatic role and the scenic function of the chorus in Aeschylean Satyric Drama, specifically in Fr. 47 to R, lines 821-832. The hypothesis of the paper argues that this choral song must be understood in dependence on the previous song of Silenus, lines 802-820, an estrophic pair with which it shows an obvious thematic relationship of complementarity. From the scenic point of view, the imbrication of the Chorus in the satyrical plot is direct and plays an actantial role that allows a scheme of integration and separation of Silenus in the choral action in an alternate movement as coryphaeus and actor.

The interaction between both lyric passages would not only be noted in the mythos and in the language but also in the gestures of the Chorus, that contribute to organize the scene.

KEYWORDS: Satyr Chorus, Gestures, Scenic Function, Satyric mythos, Silenus.

El escaso material del drama satírico que las arenas del desierto nos han conservado en papiros, no permite llegar a conclusiones exhaustivas sobre los diferentes aspectos que daban vida al componente jocoso de las tetralogías que se representaban en las Grandes Dionisíacas en el teatro de Atenas. En este sentido, el rol del Coro en las tramas satíricas es uno de los aspectos más debatidos y, paradójicamente, más especulativo, pues los fragmentos que nos han llegado no alcanzan a dar cuenta de todo lo que las fuentes antiguas nos transmiten acerca de su estética general y su resolución escénica. Sin embargo, no significa que se carezca de fuentes para avanzar en el estudio del Coro de sátiros, fuentes que Seidensticker encuadra en tres grupos: los textos dramáticos propiamente dichos, la iconografía de vasijas y los testimonios y tratados de autores antiguos. $^{1}$

Si bien no poseemos un texto teórico específico sobre el drama satírico, a excepción de los fragmentos de Camaleón de Heraclea (Fr. 37 Werhli), los tratadistas y lexicógrafos antiguos brindan información diversa 
sobre las características y la historia del género, además de datos sobre vestuario, música y danza. Un dato interesante nos lo ofrece Ateneo en el libro XIV 630 b de Deipnosofistas donde cita a Aristocles ${ }^{2}$ (en su tratado Sobre la danza) y su explicación de las características de la danza sikkinis, una danza agitada que llevó a posibles derivaciones etimológicas de su nombre de séiesthai, "agitarse”, o ingeniosamente de kinesis, "movimiento", precisamente:

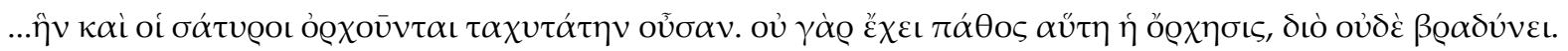

... por el movimiento velocísimo que realizan los sátiros cuando bailan. En efecto esta danza no expresa una emoción, ${ }^{3}$ por lo tanto tampoco es lenta.

Si bien la comparación con la danza pírrica es llamativa, visto que esta es una danza guerrera y noble mientras que la sikkinís es licenciosa, Platón en Leyes. VII. 815 c-d asigna esta característica a las danzas báquicas en general:

ő

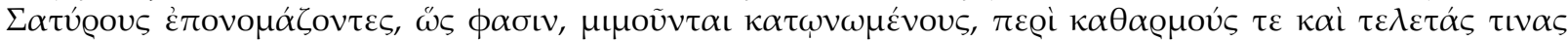

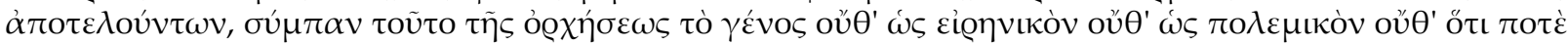

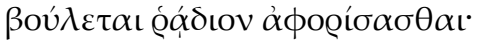

Toda la que es bacanal y las danzas relacionadas, con las que imitan, así dicen, a ebrios, dándoles el nombre de Ninfas, Panes, Silenos y Sátiros, mientras realizan purificaciones y ritos iniciáticos, a todo ese género de la danza no es fácil definirlo ni como pacífico ni como guerrero, ni determinar lo que pretende.

Esta característica de movimiento agitado, ruido y golpeteo es usualmente referida en las obras, por ejemplo en Rastreadores de Sófocles (vv. 221-222):

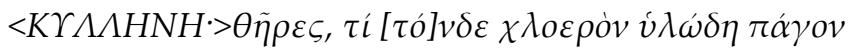

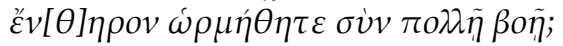

(CILENA) Bestias, ¿por qué irrumpis con tan gran alboroto en esta verde y selvosa colina habitada por fieras?

La ninfa sale de la gruta atemotrizada por los ruidos y golpeteos de los cascos de las patas de los sátiros en el suelo, destacando esta característica del coro. ${ }^{4}$ Más evidente es esta característica en el ingreso del coro de sátiros en el Cíclope de Eurípides (vv. 36-40):

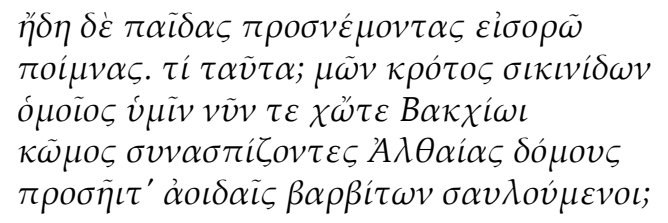

(Sileno) Pero he aqui que veo a mis hijos que conducen

los rebaños a casa. ¿Qué es eso? ¿Es momento ahora para vosotros

de hacer sonar el suelo al son de la sikinis,

como cuando, acompañando a Baco en su festivo cortejo,

os dirigiais a la casa de Altea,

moviéndoos con voluptuosidad a los acordes de los cantos de vuestras liras?

Movimiento acelerado, ruido y voluptuosidad son las caracaterísticas que sirven para presentar el ingreso de un coro en el drama satírico. ${ }^{5}$

Estas descripciones de los movimientos en la escena responden a características teatrales que se han desarrollado en la historia del drama satírico, en la que Esquilo juega un papel fundamental, o más bien, 
seminal. Si la $V i d a$ de Esquilo destaca que el poeta de Eleusis introdujo el segundo actor en la escena trágica, esto no debió ser inocuo respecto del drama satírico. Semejante cambio, seguramente, hizo que los sátiros asumieran nuevos roles y funciones teatrales, pero, a mi entender, modificó especialmente la noción de mythos satírico, pues para un nuevo rol, el poeta debía encontrar la trama propicia para el geloîon propio del género.

En esta nueva trama el coro mantuvo el protagonismo que, con el paso del tiempo, fue perdiendo hasta llegar a ser prácticamente un accesorio burlesco, como en el Cíclope de Eurípides (Di Marco, 1991, p. 44). Así, los fragmentos del drama satírico esquileo distinguen el coro no solo por la danza movediza sino también por su participación en el desarrollo de los episodios junto a los actores y a Sileno. Como primer ejemplo, puede retomarse el que ofrece Seidensticker (2003, p. 101) de Prometeo encendedor del fuego de Esquilo (Fr. 204 b R, vv. 1-5):

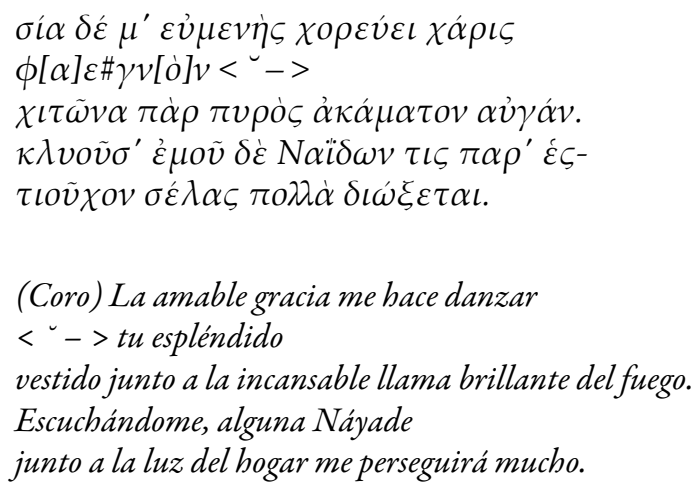

Al ver la llama de fuego que Prometeo ha escondido en la caña como regalo para los mortales, los sátiros se ven compelidos a danzar a su alrededor de manera alterada, pensando incluso que esto atraerá a las Náyades.

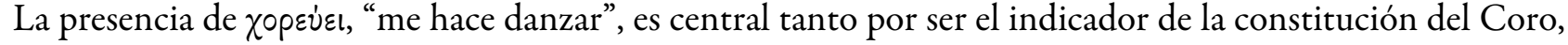
y por ende del canto coral, cuanto por hacer evidente que no es la expresión de un páthos que mueve a un canto solemne, sino una acción desbordada que pone de manifiesto la directa relación de dicho canto con los sucesos episódicos. La imbricación del canto y la trama es tal que el mismo Prometeo advierte a los sátiros que este fuego que desconocen puede causarles un mal, dado que en su mímica (gestos y movimientos) se acercan demasiado (Fr. 207 R):

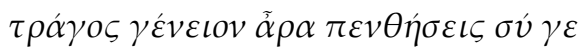 \\ Cabra, tú lamentarás la barba}

La misma excitación que los impulsa al canto coral y a la danza báquica y descuidada puede producirles un mal en tanto no están bailando solos en la orquesta sino que lo hacen junto al fuego y a la obvia presencia de Prometeo.

Este ejemplo de la intervención del coro de sátiros en Prometeo encendedor del fuego coincide con otras obras de Esquilo y Sófocles y muestra una característica que ya no es reconocible en el Cíclope de Eurípides: en el caso de los dos primeros autores el coro de sátiros y sus acciones tienen un rol dramático central en cuanto, proponemos como hipótesis, el mito es el marco contextual cuyo avance depende en gran parte de la acción de los sátiros (incluido Sileno); en Eurípides, en cambio, la trama del mito se mantiene como eje central y el coro irrumpe en ella, en momentos precisos, sin alterarla.

Una situación análoga a la de Prometeo encendedor del fuego la vemos en Los emisarios, donde el Coro de sátiros pretende llegar a ser un atleta y alejarse de su señor Dionisio. Precisamente, el dios de la danza báquica les recrimina "esta independencia" que no se condice con momento alguno de la historia mítica de Dionisio, 
y los insta a retomar las actividades habituales, es decir a mantener los límites de una trama que responda $a$ priori a la expectativa de los espectadores (Fr. 78 a R, vv. 32-33):

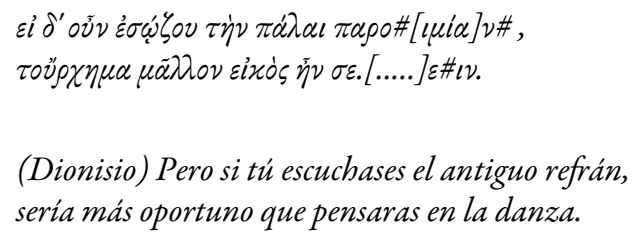

La inconsistencia entre la figura visible de los sátiros y su pretensión atlética es motivo suficiente para la hilaridad. Pero no es menos llamativo el hecho de que el Coro pretenda realizar en la orquesta algo que le es completamente inusual, dejando de lado lo que de él se espera en el teatro. Esto hizo que la tradición reconociera a Esquilo como el mejor de todos los satirógrafos, pues sus coros de sátiros generaban la complicación dramática y hacían del mýthos algo interesante para ser representado, lejos de ser un coro que solo asistiera a ella. ${ }^{6}$

Este rasgo diferencial, a mi juicio, es necesario para entender la intensa relación dialógica y dramática que los fragmentos de Esquilo nos presentan entre el coro y los personajes a partir de lo cual, y en consecuencia, la trama que resulta no es un recorte del mito con sátiros, sino un coro de sátiros forzando el avance de las acciones para cambiar su dirección. Esto se ensambla mucho mejor con las características generales que la crítica reconoce a los sátiros como seres particulares del mito y el folclore, con sus ambigüedades y, especialmente con la definición de Di Marco de la impoliticità de este coro, es decir, con la insistente preocupación por actuar en las ocasiones y modos que requiere la pólis, pero con soluciones ridículamente equívocas.

Precisamente, y retomando el ejemplo de Prometeo encendedor del fuego, el coro de sátiros pretende redireccionar la trama insistiendo en lo que genera en ellos y en las Náyades. El canto coral del Fr 204 b muestra que el coro busca dar forma a la trama: Prometeo muestra el fuego que dará a los mortales, y el Coro, lejos de entonar una canto que hable de semejante hecho cultural de manera distante o reflexiva, lo convierte escénicamente en acción misma de bailar de manera agitada, proyectando las consecuencias de la posesión del fuego en lo que supuestamente provocará en las Náyades (y en su propio beneficio): un deseo de perseguir el fuego y con ello de perseguir a los sátiros. La imbricación del canto coral, como acción coral, con la trama es completa: los sátiros centran el tema del canto en el beneficio que esto les traerá al ser acosados por las Náyades que, usualmente, se escapan de ellos. Los sátiros se sienten tan dueños del fuego como Prometeo y por ello tienen plena seguridad, y así lo anticipan en su canto, de que las Náyades se sentirán atraídas hacia ellos. ${ }^{7}$

Esta característica del coro satírico de Esquilo (y de Sófocles) responde también a una norma del género: el coro de sátiros posee siempre la misma identidad y es en la imbricación en la acción que gana un rol específico. El coro trágico, cuyo rol está condicionado por la trama de la obra, a la que no pretende modificar ni redireccionar, posee una identidad afirmada en las características puntuales en cada obra: ancianos, mujeres esclavas, jóvenes vírgenes, marineros, etc. Pero el coro de todo drama satírico es exactamente el mismo coro compuesto de sátiros que tiene en la figura de Sileno un nexo con los protagonistas. No es sencillo generar expectativa por medio de un coro repetitivo. Pero son dos las estrategias exigidas por el género: que los sátiros asuman un rol interno producto de la situación dramática y que no se atengan a la trama del mito, sino que intenten transgredir sus límites narrativos. En el primer caso, observamos que el coro define su identidad de acuerdo a la situación que les permite irrumpir en la trama específica. Así, por ejemplo, los sátiros serán arrastradores de redes cuando sean convocados a ayudar a sacar una pesada red del mar, o, en otra ocasión, serán sabuesos cuando el robo de las vacas de Apolo les brinde la oportunidad de convertirse en los "héroes" recuperadores del ganado del que parece desvalido para lograr lo que en el Himno Homérico a Hermes realizara completamente solo. ${ }^{8}$ 
Los testimonios que poseemos no permiten afirmar de manera concluyente que los sátiros incluyeran un vestuario que sirviera para caracterizar su rol en la obra. Pero las imágenes de vasijas muestran algunos sátiros con elementos que permiten reconocer un rol concreto en una trama. Así, en algunas ocasiones, el coro de sátiros define la expectativa del espectador por medio del recurso visual. Mientras que en la tragedia hay una profunda interacción psicológica con los protagonistas, en el drama satírico, el elemento visual del vestuario, del movimiento y, especialmente, del gesto, es decir la ópsis, es el elemento escénico más destacado. Así, las escenas de parodia en los dramas satíricos esquileos debieron ser recurrentes, como los sátiros parodiando cerdos en Circe o focas en Proteo. Un vestuario tal como el descrito haría aún más evidente la imbricación del coro en la trama, pues, como sabemos, la presencia de los sátiros en estas es circunstancial y responde en gran mediada a su naturaleza folclórica de ser habitantes de los márgenes. ${ }^{9}$

El coro de Prometeo encen dedor del fuego no parece estar vestido de manera especial ni conocemos el motivo para su presencia en los $\dot{\varepsilon} \sigma \chi \alpha \tau \dot{\alpha}$, es decir que no tenemos datos que lleven a pensar que son esclavos de alguien cuando Prometeo les muestra el fuego que habrá de darles a los pastores. ${ }^{10} \mathrm{Si}$ hacemos caso al escolio a Trabajos y días de Hesíodo, verso 89 (=Aesch. Fr. ${ }^{* *} 207$ a R), en esta obra son los sátiros quienes entregan a Prometeo la vasija con los males con los que los dioses planean castigar a los humanos. Pero el coro se descontrola por el héurema del fuego y prevé que las Ninfas y Náyades lo seguirán a su hogar. Yziquel (2001, p. 10) entiende que el Coro afirma que se constituirá un thiasos en este "ambiente pastoral” y Jiménez Justicia

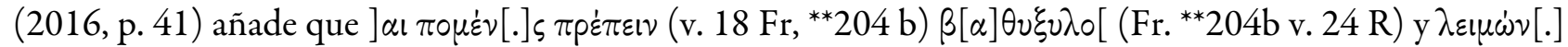
(Fr. ${ }^{* *} 204$ c v. $2 \mathrm{R}$ ) indica que los sátiros planean sumarse a la celebración de los pastores en el ámbito del bosque. Una mímica de danza de thíasos, al modo satírico, garantizaría el intento del coro de hacer del fuego un elemento unificador de pastores, sátiros y ninfas, creando una escena del todo dispar a la presentación hesiódica del tema.

Sostuve antes que el Coro quiere mostrar una escena en la que es objeto de deseo sexual por parte de las Náyades y Ninfas, y esto sería posible porque, a diferencia del relato hesiódico, los sátiros asumirían que son ellos los primeros a quienes Prometeo ha mostrado el fuego, por lo que asumen el rol de intermediarios entre el Titán y los hombres, un rol desconocido en el mito pero que les permite desplegar su propio mýthos: como dadores del fuego convivirán con los pastores y organizarán danzas nocturnas.

La imagen que se crea en el canto coral es la de un mundo ideal para los sátiros, mientras que por la trama hesiódica sabemos que llegará el error de Epimeteo y la consecuente desgracia de los mortales. Así, el coro de sátiros, lejos de un canto coral en el que se evalúa la importancia del fuego o se comenta la acción de Prometeo, da pie a imaginar una situación que tensiona la tradición mítica y trata de crear un mýthos en el que ellos jugarían un rol central, hecho que, por supuesto, no se concretará. El Coro de sátiros no pretende incluirse en la tradición épica de Hesíodo y, entonces, busca crear su propia trama. ${ }^{11}$

La adaptación del modelo épico a la escena satírica no implica para el caso de Esquilo una subordinación del coro al momento épico de la trama. En este sentido, el Cíclope de Eurípides no puede ser tomado como modelo invariable del género, pues en esta obra el Coro de sátiros se inserta en una subtrama cómica. Por ejemplo, a partir del v. 590, Odiseo sale de la cueva de Polifemo anunciando que el vino dominará pronto al Cíclope y será momento de preparar el tizón para cegarlo. El Coro de sátiros canta el tercer estásimo (vv. 608-623):

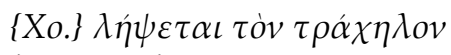

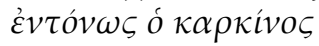

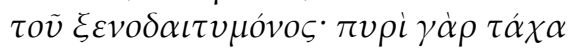 \\ $\phi \omega \sigma \phi o ́ \rho o v \varsigma ~ o ̉ \lambda \varepsilon \tilde{\imath}$ кó $\alpha \varsigma$.

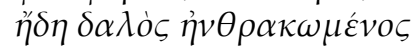

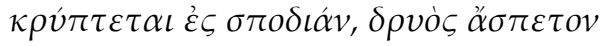

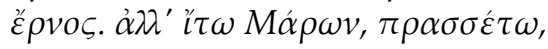 \\ $\mu \alpha \iota v o \mu \varepsilon \dot{v o v}$ ' $\xi \varepsilon \lambda \varepsilon \dot{\tau} \tau \beta \beta \dot{\varepsilon} \phi \alpha \rho o v$
}




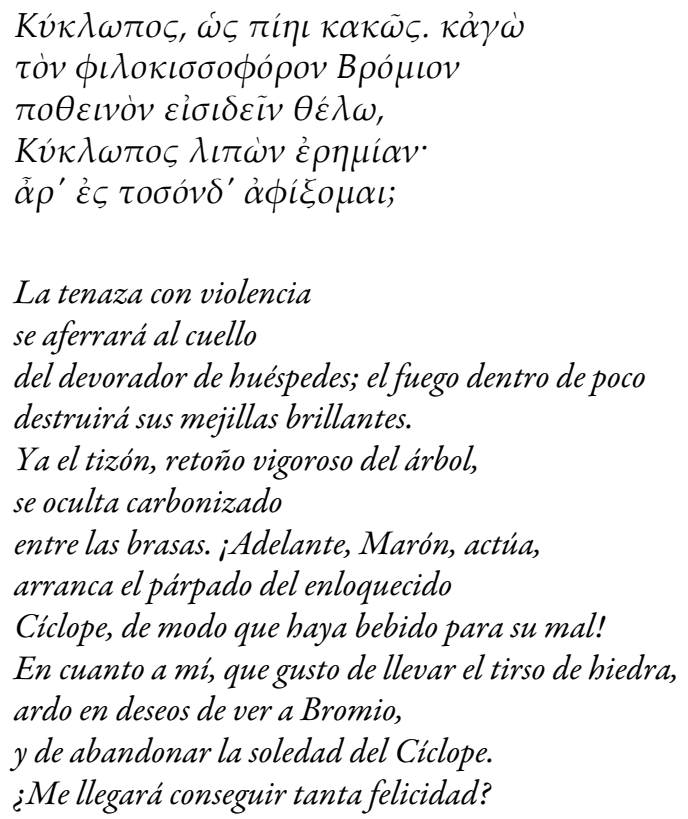

En este breve canto astrófico el Coro retoma el tema de su esclavitud y se anticipa el cegamiento de Polifemo pero no se observa ninguna intención de reconducir la trama hacia un punto distinto al de Odisea. Incluso, cuando esté todo dispuesto para concretar la hazaña, el Coro se negará a participar de las acciones, situación a través de la cual Eurípides juega con el tópos de la cobardía de los sátiros y sus excusas para no colaborar con los marineros, pero, al mismo tiempo, es una estrategia que le permite respetar un punto central de la trama homérica: el Cíclope es vencido por la sola astucia de Odiseo y la valentía de sus marineros.

Esto es bien distinguido por Eurípides cuando Odiseo, frente a la negativa de los sátiros de arriesgarse en la acción de cegar a Polifemo, les pide que, al menos, ofrezcan un canto que dé valor a los hombres que asumirán la empresa. El Coro ofrece el siguiente canto (vv. 655-662):

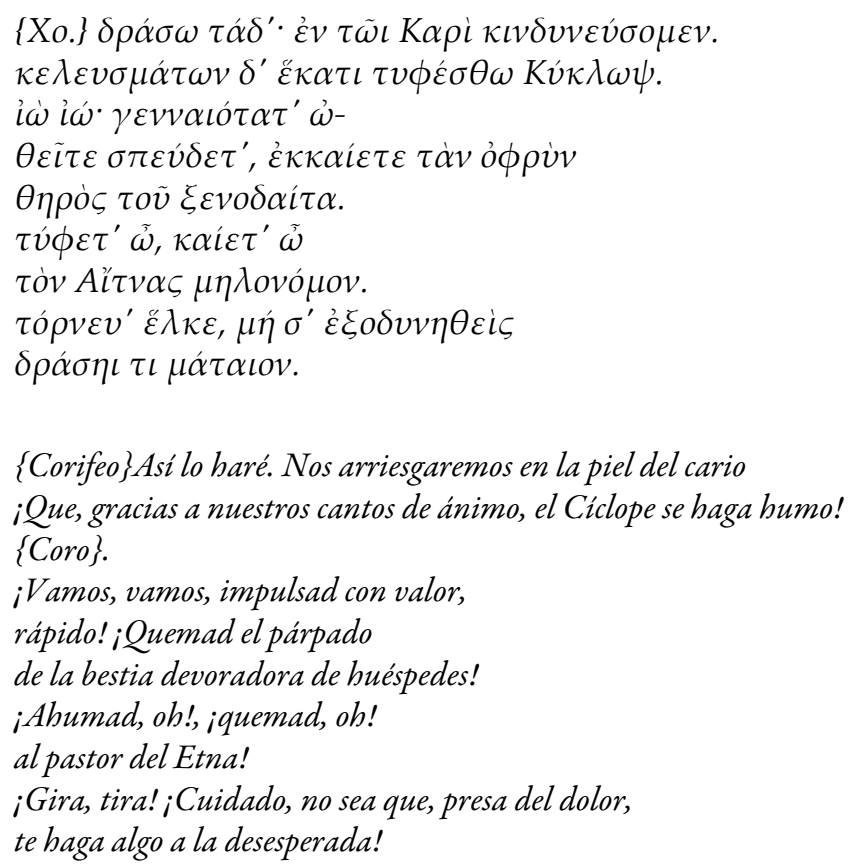

Este canto de "marineros" es un ejemplo claro de la inserción de motivos líricos populares en el drama satírico. ${ }^{12}$ Aquí el Coro se limita a hacer visible al espectador lo que está sucediendo en el interior de la 
caverna, pero en ningún caso participa de la acción, lo que, insisto, resulta un respeto riguroso a la trama épica homérica.

Veamos un nuevo caso a mi juicio similar y que apoya la idea de que este tipo de intervenciones de cantos corales era regular en el género satírico, pero que en Esquilo tenía una función más ligada a la trama del mito. ${ }^{13}$ El Fr. 47 a R de Arrastradores de Redes ofrece uno de los pasajes más extensos del drama satírico de Esquilo, con una sección episódica en la que Sileno, deseoso de poseer a Dánae, se propone a sí mismo como próxenos de la bella joven y su pequeño hijo Perseo (vv. 765-772). De inmediato, Dánae rechaza el asedio de Sileno con un duro parlamento en el que pide a Zeus que la proteja de estas bestias ya que el dios, como padre de Perseo, le ocasionó males que ahora se renuevan (vv. 773-785).

Sileno, entonces, se dirige al niño Perseo, que asiste a la escena en silencio pero que al ver al padre de los sátiros se ríe en primer término, para luego llorar. Sileno intentará disuadirlo del llanto con un canto lleno de imágenes pastoriles, que cautivarían más a la madre que al niño, pero con un ritmo y movimiento físico que tranquilizarían al pequeño Perseo.

La asignación de estos versos a Sileno es materia discutida. Dettori detalla las posiciones y argumentos expuestos y concluye que la propuesta de Siegmann (1948, p. 13) de Sileno como persona loquens es la más aceptable. ${ }^{14}$ Aún cuando hay propuestas que asignan estos versos al Coro, concuerdo con el análisis integral de los versos y las conclusiones de Dettori.

Chourmouziades, por su parte, defiende la atribución al Coro y su principal argumento es que no tenemos otra evidencia en el drama satírico en el que Sileno cante un pasaje lírico. ${ }^{15}$ Este argumento es ciertamente discutible pero, en vistas al análisis que estamos haciendo acerca de la participación del coro, nos permite indagar la posición de Sileno frente al Coro a partir de su estatus ambiguo de corifeo y actor. Por una parte, Sileno como padre de los sátiros tiene algunas características propias de sus hijos, es decir, es un sátiro de mayor edad; en ocasiones actúa como portavoz del coro y otras veces lo hace por su lado, incluso en oposición a sus hijos. Por ello, es difícil evaluar si Sileno es un actor independiente, un corifeo o un "tertium quid" entre el coro y los actores. ${ }^{16}$ Esto podría haber ocurrido por el desarrollo histórico del género en el que Sileno, como desprendimiento del coro de Sátiros, mantuvo su lugar de corifeo y fue paulatinamente asumiendo un lugar de actor que pudo cristalizarse por influencia de la inclusión del tercer actor en la tragedia.

En el caso de Arrastradores de redes de Esquilo, esta canción de Sileno reúne algunas características propias de un coro: en primer lugar, a partir del verso 802 , entona una canción que puede considerarse una canción de cuna con la que intenta calmar el llanto de Perseo. ${ }^{17}$ Este tipo de canción sería equivalente al canto de remeros del Coro en el Cíclope de Eurípides, pero con diferencias claras: en el caso de Eurípides el coro responde al pedido de Odiseo de alentar a los marinos a actuar con valor y, estructuralmente, pone de manifiesto lo que sucede en el interior de la cueva y llena el espacio temporal entre el ingreso y la salida de la caverna por parte de Odiseo. ${ }^{18}$ En el caso de Arrastradores de redes, el canto de Sileno está lejos de ser una transición entre dos episodios, pues el intento de Sileno de calmar al niño mira directamente a Dánae, a quien quiere cautivar con los placeres que le promete (vv. 808-811) y mostrar sus cualidades de padre y educador de

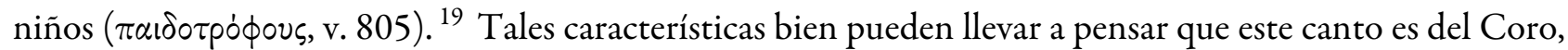
precisamente porque la idea de Sileno de desposar a Dánae es compartida por el Coro que reclamaría a la joven como pago por haber colaborado en su rescate.

Tanto el hecho de que Sileno y el Coro compartan su objetivo, cuanto que Sileno haya asumido una forma lírica propia de un coro de sátiros, muestra que en Esquilo (o al menos en Arrastradores de redes) Sileno no se distingue de manera neta del Coro y este último opera en la trama junto a Sileno con sus propios objetivos, más allá de los trazos centrales de la tradicional saga de Perseo. ${ }^{20}$

En efecto, considero que si se observa el avance argumental entre la (posible) canción de cuna de Sileno y el canto coral que le sigue (vv. 821-832), esta "introducción a" o "canto de" himeneo es una clara continuidad 
respecto de lo expresado por Sileno, mientras que sus cambios métricos, lingüísticos y estilísticos responden con mayor certeza a la naturaleza coral del canto: ${ }^{21}$

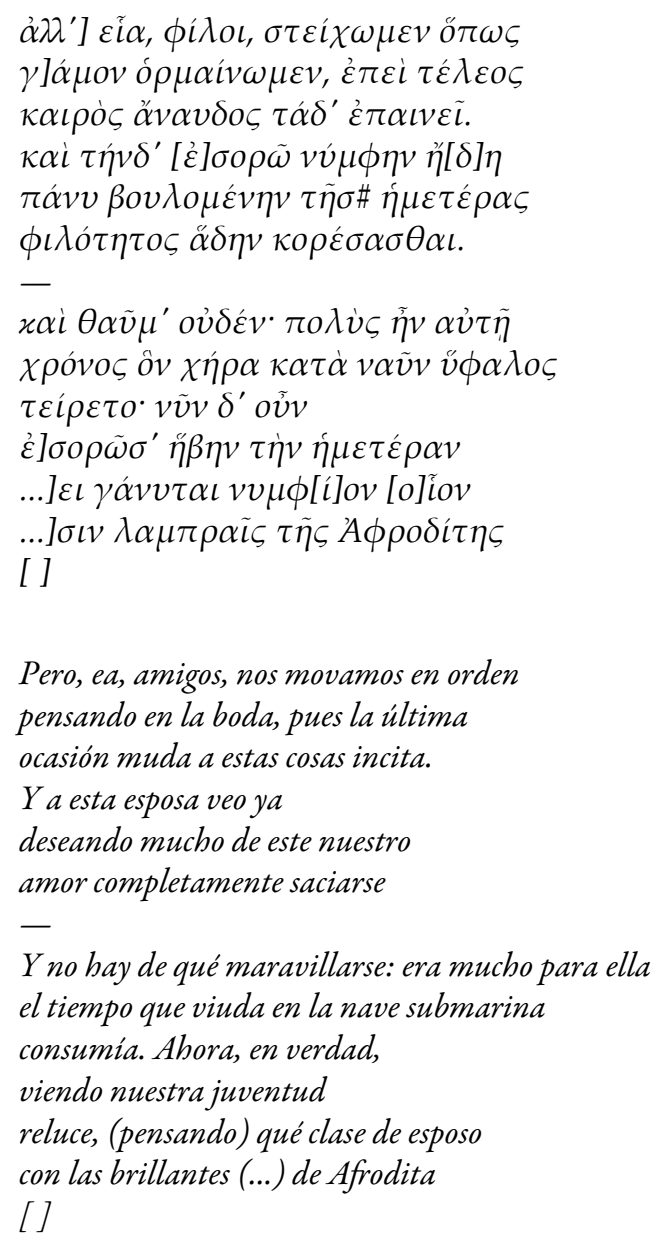

Más allá del éxito del canto de Sileno sobre Perseo, los sátiros actúan de inmediato, sin demoras y sin mediar ninguna indicación o anuncio del canto que es, por tanto, una continuidad de la acción bajo la forma de canto coral.

Desde el punto de vista de la estructura de la obra y frente a las diversas posibilidades defendidas, concuerdo con Taplin al considerar este canto como una "falsa partida": en ausencia de Dictis, Dánae se encuentra sola con Sileno y el Coro, quien anuncia la celebración del matrimonio del que ellos también obtendrán la convivencia. Pero en el momento en que el Coro se está retirando, regresaría Dictis a escena para salvar a la joven de los sátiros y reconducir el final de la obra: "The lines are anapestic, and may well have been acompanied with coreography wich suggested imminent departure; with these lines the play is evidently drawing to a close, a false close."(Taplin, 1977, p. 419).

La propuesta de Taplin trae a colación el problema del tercer actor pues, si Dictis reingresa junto a Dánae y Sileno, entonces sería necesario admitir tres actores en la escena. La ausencia de indicaciones de salidas de actores es regular en el drama satírico de Esquilo y Sófocles (y un elemento distintivo respecto de la tragedia, según Taplin, 1977, p. 57), por lo que es complejo formular una hipótesis sobre los movimientos de actores que, por lo demás, suelen reordenarse en torno a los cantos corales astróficos, como podría ser el presente caso.

Para Dettori (que argumenta con impecables criterios lingüísticos) el canto podría ser asignado al Coro o al Corifeo. ${ }^{22}$ Partiendo de la aceptación de la lectura de Dettori, es preciso contemplar algunas propuestas que establecen una relación coral y escénica con el anterior canto de Sileno. Wessels-Krumeich sostienen que 
los versos 821-826 podrían estar en boca de Sileno, mientras que el Coro, luego del parágraphos, comentaría este pedido de su "líder" de organizar la procesión de gámos (Krumeich et al., 1999, pp. 107-124, esp. 118).

Esta propuesta a mi juicio tiene el mérito de no separar completamente el canto anterior de Sileno (vv. 786-820) del canto actual del Coro. En efecto, aún cuando asignamos los versos 821-832 al Coro, es posible leerlos en función de la anterior intervención de Sileno: el padre de los sátiros intenta calmar el llanto de Perseo y ganarse con ello "el amor" de Dánae. El Coro podría "dar continuidad" al canto de Sileno con alguna mímica en su danza, lo que resultaría visualmente, en conjunto, un canto de un "corifeo" con la danza de su coro. De esta manera, cuando el Coro resuelve "pensar en la procesión matrimonial", Sileno no está totalmente separado del Coro de sátiros y así, al momento del ingreso de Dictis para evitar la acción de los sátiros, Sileno estaría unido al Coro y dejaría de "funcionar" netamente como actor. ${ }^{23}$

Como hemos visto la danza del coro de sátiros suele ser espontánea y provocada por un suceso que considera admirable. Este suceso en Arrastradores de redes no sería un héurema como el fuego de Prometeo encendedor del fuego o el misterioso sonido de la lira como Ichneutae de Sófocles, sino el matrimonio de Sileno y su consumación grupal.

La decisión del Coro de emprender la procesión nupcial no es un pedido de Sileno, sino una iniciativa propia del coro, independiente, que busca concretar un gámos. Por supuesto, lo hace siempre con las características de un coro satírico, como propongo entender el pasaje.

En primer lugar el verbo $\sigma \tau \varepsilon i \chi \omega \mu \varepsilon v$ implica la toma de decisión de llevar a cabo la procesión y el gámos, en principio para cumplir con el deseo de Dánae, que se regocija al ver la lozanía viril de los sátiros. Es muy

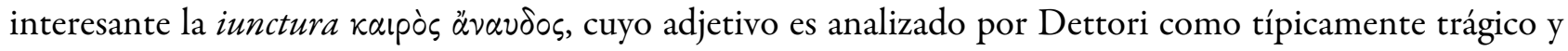
predilecto de Esquilo, quien es el único que lo usa en referencias no personales (Dettori, 2016, p. 193). Para este comentarista " $\not \nu \alpha v \delta \circ \varsigma$ è un segnale visivo, che trasmette un messaggio. Non è esattamente la stessa cosa qui, poiché il kaıpós in sé non è un segnale visivo né ne invia” (Dettori, 2016, p. 193).

Sin embargo, el kaıpós en la presente situación podría ser un posible gesto de Dánae horrorizada por el acoso o negando la efectividad del intento de Sileno de calmar a Perseo, y que el Coro interpreta como una mirada deseosa y un gesto hacia su evidente falo. En ese caso, habría una efectiva señal visual (el gesto de Dánae) cuyo mensaje el coro decodifica erróneamente. ${ }^{24}$ Tal gesto puede ser deducido a partir del deíctico $\tau \dot{\eta} \nu \delta^{\prime}[\dot{\varepsilon}] \sigma \circ \rho \tilde{\omega} \nu \dot{v} \mu \phi \eta \nu$, que no es una indicación de ingreso de un personaje sino una focalización sobre quien, a mi entender, realiza los gestos. ${ }^{25}$

En la interpretación que propongo, el juego de equívocos entre los gestos de horror de Dánae y la decodificación de estos que el Coro realiza, implica una deliberada distinción de la presente escena con la tragedia. En efecto, como muestra el T 1,25-26 R, Esquilo se destaca por el gusto por el teratódes, y creo que el coro de Euménides da cuenta de que la focalización de este aspecto en el coro era una práctica habitual. En el caso de Euménides la construcción del coro como dramatis persona incluye el horror visual, el terror discursivo y el poder divino que no precisan mediaciones entre lo que escena proyecta y phóbos que se produce hacia y en el espectador. ${ }^{26}$ En el presente caso, en cambio, es Dánae la que debe hacer los gestos de horror frente a Sileno y los sátiros, pero la identidad ridícula del coro de sátiros nunca es puesta en dudas por parte del espectador, de manera que Esquilo genera una tensión poética entre la posibilidad moldear un coro (en la tragedia) y de utilizar un coro estéticamente estereotipado (en el drama satírico).

El Coro piensa en disponer la procesión movido por los gestos de Dánae que, desde su lectura errónea, está

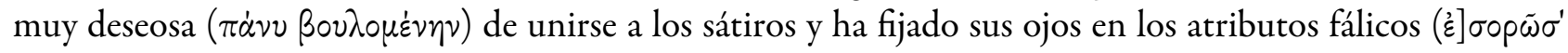
$\ddot{\eta} \beta \eta \nu \tau \dot{\eta} \nu \dot{\eta} \mu \varepsilon \tau \dot{\varepsilon} \rho \alpha \nu) .{ }^{27}$ Aunque de manera arbitraria, propongo leer el adverbio $\pi \dot{\alpha} \nu v$ como un indicador de los gestos de Dánae. En efecto, los sátiros debieron haber oído el relato de la joven del largo tiempo transcurrido en el arca en la que llegara a Sérifos, por lo que sus gestos de horror y rechazo (quizá ampulosos) "confirman" que la abstinencia de actividad sexual y el falo prominente generan un deseo “intenso" ( $\pi \dot{\alpha} \nu v)$ en Dánae. 
Así como Sileno desde su ambigua posición canta como si fuera un segundo actor en la escena para luego reinsertarse en el grupo coral, la acción del Coro no solo es independiente de cualquier orden de Sileno sino que tiene sus propios objetivos. Efectivamente, Sileno promete a Perseo una vida de pastores y compartir el lecho con Dánae (vv. 810-811):

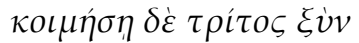

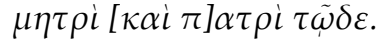

Te acostarás, tercero, con tu madre y este padre.

El verbo кoн $\tilde{\alpha} \sigma \theta \alpha \iota$, “acostarse”, tiene un doble sentido y destinatario: acostarse-copular/ Perseo-Dánae respectivamente. Sileno, de manera sutil, hace evidente que toda la canción tiene como finalidad última

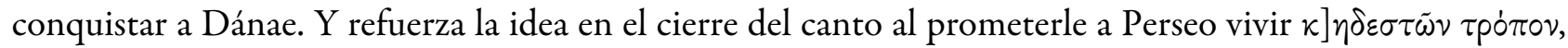
"al modo de parientes", que como expresión técnico-legal, se refiere a diferentes relaciones parentales o a la "parentela" en general, lo que significa, como concluye Dettori, que es el mismo Sileno quien llegará a ser ese "pariente" aludido. ${ }^{28}$ De hecho el enfático $\tau \tilde{\omega} \delta \delta \varepsilon$ del verso 811 y o $\pi \dot{\alpha} \pi \alpha \varsigma$ ("papito”, v. 789) ponen de manifiesto que en su canto Sileno insiste en que él mismo será el esposo de Dánae, expresándolo con un cierto nivel de imprecisión terminológica propia del personaje y del género.

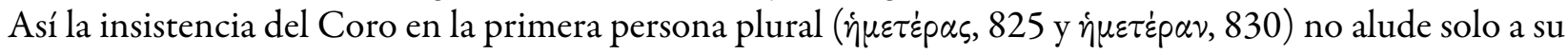
composición grupal sino también a la reafirmación frente a Sileno de que las nupcias lo incluyen de manera efectiva. La procesión matrimonial que va a llevarse a cabo tendrá a los sátiros como un esposo visiblemente atractivo. Entiendo que, más allá de la resolución sintáctica, [o] iov puede estar acompañado de un gesto que

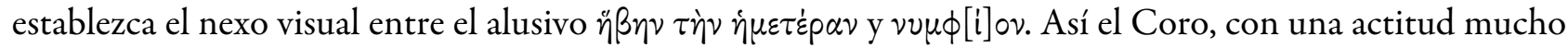
más incisiva respecto de Dánae, no acompaña la estrategia de Sileno de captar a Perseo, sino que pone su “juventud" por delante como mecanismo de persuasión sobre la muchacha.

Esto se refuerza con el análisis de la partitura métrica que analiza Cerbo, quien señala que el foco y la insistencia en la muchacha se refuerzan con la misma posición métrica de $v \dot{u} \mu \phi \eta \nu$ (v. 824) y $\nu v \mu \phi[i] \circ \nu$ (v. 831).

En consecuencia, el canto anapéstico del Coro tendría una función dramática diferenciada de la del canto estrófico de Sileno (compuesto por ferecracios y gliconeos): Sileno con un canto acompasado, alegre y en un registro lingüístico elevado (aún con el juego de doble sentido que señalamos respecto del verbo koıjã $\sigma \theta \alpha \iota)$ se muestra como un padre ejemplar y educador (recordemos que es nada menos que Perseo quien está en sus manos), mientras que el Coro con un posible uso mayor de la gestualidad, apura la escena para comenzar a

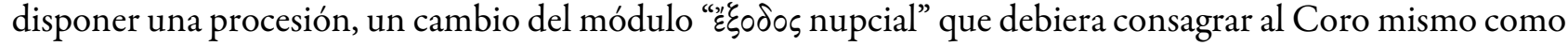
esposo de Dánae, una salida completamente inesperada tanto en el mito de Perseo (cuyo drama matrimonial se centra en Dánae y Polidectes) cuanto en la trama dramática que conducía a que solo Sileno reclamase como esposa a la joven salida del arca.

En conclusión, toda la sección de los versos 786-832 debía constituir un gran efecto escénico y musical por la alternancia de ejecutores, de expresión (primero lírica, luego recitativa), de articulación estructural (sección astrófica, estrófica, antistrófica y un sistema anapéstico) cuya brusca interrupción estaría dado por el ingreso de Dictis, hecho que también evidencia una interrelación profunda entre el Coro y los personajes en las tramas satíricas esquileas. ${ }^{29}$

Hemos visto que en cierta forma el Coro realiza una suerte de responsio temática con el canto de Sileno. La mayor libertad para intersecar secciones recitativas con líricas da cuenta de la ductilidad del espectáculo musical del coro satírico que acompañaría su canto con movimientos más punzantes que los de un coro de tragedia. De esta manera, Esquilo parece contraponer el coro satírico, con mayor implicación en la trama, al 
coro trágico, que reacciona emotivamente frente a los sucesos. Esto, evidentemente, tendría como efecto una redefinición del impacto que la música, el gesto y la danza tenía en las tragedias previamente representadas. ${ }^{30}$

El intento del Coro de sátiros de Arrastradores de redes de llegar al matrimonio con Dánae fracasaba, pero su insistencia en determinar las acciones reafirmaba la primacía coral al mediar entre la historia conocida por el espectador y una posible resolución que se apartara de ella. ${ }^{31}$ La imagen, los equívocos lingüísticos y gestuales y la tradicional y característica incapacidad de los sátiros hacía que este, como todos sus otros intentos, generaran una reacción jocosa que distendía las tensiones de los coros trágicos, fuertemente afectados por las acciones y emociones de los personajes en las obras previamente representadas. ${ }^{32}$

\section{REFERENCIAS}

Cerbo, E. (2015). Metro e ritmo nel dramma satiresco (V-IV a. C.). SemRom, 4, 71-117.

Collinge, E. (1958-1959). Some Reflections on Satyr Plays. PCPhS, 5, 28-35.

de Dios, L. (2008). Esquilo. Testimonios. Fragmentos. Madrid: Gredos.

De Santis, G. (2005). Las Erinias: configuración progresiva del personaje y definición simbólica en Orestíada de Esquilo. Primera parte. Ordia Prima, 4, 37-74.

Edmunds, L. (1994). Tragedia, drama satírico y folklore. Mito y literatura. Revista de Occidente, 158-159, 43-58.

Gagné, R. y Govers Hopman, M. (2013). Choral Meditations in Greek Tragedy. Cambridge: Cambridge University Press.

Halleram, M. (1989). The Speaker(s) of Aeschylus, Dictyoulkoi fr. 47 a Radt (= P. Oxy. 2161). ZPE, 79, 267-269.

Jiménez Justicia, L. (2016). Ecos épicos en el drama satírico de Esquilo y Sófocles de temática pastoril. Ágora. Estudos Clássicos em Debate 18, 33-57.

Kamerbeek, J. C. (1954). De Aeschyli Dictyulcis. Mnem, 7, 89-110.

Kousoulini, V. (2015). A satyric lullaby in Aeschylus' Net-Haulers (fr. 47a Radt)?. Euphrosyne, 43, 9-22.

Krumeich, R. et al. (1999). Das griechische Satyrspiel. Darmstadt: Wissenschaftliche Buchgesellschaft.

Melero, A. (1991). El mito del drama satírico. Fortunatae, 1, 85-102.

Napolitano, M. (2000). Odisseo simposiarca fraudolento e Polifemo simposiasta raggirato nel Ciclope di Euripide. En Arrighetti, G. (Ed.), Letteratura e riflessione sulla letteratura nella cultura classica (Atti del Convegno Pisa, 7-9 giunio 1999) (pp. 51-63). Pisa: Giardini Editori.

Palmisciano, R. (2008). Il meccanismo della distensione nel Ciclope di Euripide. AION (filol.), 30, 65-85.

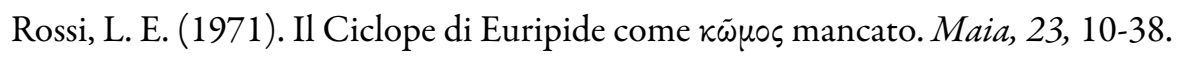

Rossi, L. E. (1991). Il dramma satiresco. Dioniso, 61, 11-24.

Seidensticker, B. (2003). The Chorus in Greek Satyrplay. En Csapo, E. y Miller, M. (Ed.) Poetry, Theory, Praxis. The Social Life of Myth, Word and Image in Ancient Greece. Essays in honor of William Slater (pp. 100-121)Oxford: Oxbow Books.

Shaw, C. (2015-2017) The never-ending chorus: repetition and innovation in Greek Satyr Drama. Ordia Prima, 14, $115-158$.

Sutton, D. F. (1974). Silenus: Actor or Coryphaeus? CQ, 24, 19-23.

Taplin, O. (1977). The Stagecraft of Aeschylus: The Dramatic Use of. Exits and Entrances in Greek Tragedy. Oxford: Clarendon Press.

Thompson, W. (1971). Attic Kinship Terminology.JHS, 91,110-113.

Voelke, P. (2001). Un Théâtre de la Marge. Aspects figuratifs et configurationnels du drame satyrique dans l'Athènes classique. Bari: Levante Editori. 


\section{EDICIONES Y COMENTARIOS}

Cipolla, P. (2003). Poeti minori del dramma satiresco. Testo critico, traduzione e commento. Amsterdam: Adolf M. Hakkert Editore.

Dettori, E. (2016). I Diktyoulkoi di Eschilo. Testo e commento. Contributo a la lingua e stile del dramma satiresco. Roma: Edizioni Quasar.

Napolitano, M. (2003). Euripide. Ciclope. Venecia: Marsilio Editori.

Radt, S. (1985). Tragicorum Graecorum Fragmenta, Vol. 3: Aeschylus. Göttingen: Vandenhoeck \& Ruprecht.

Seaford, R. A. S. (1984). Euripides. Cyclops. Oxford: Clarendron Press.

Werre-de Haas, M. (1961). Aeschylus' Dictyulci. An Attempt of Reconstruction of a Satyric Drama. Leiden: Brill.

\section{Notas}

1 Todavía es actual el panorama que ofrecen Seidesnticker y Krumeich et al. (1999), en sendas introducciones, p. 1-40 y p. 41-73, respectivamente, a lo que se debe añadir Cipolla (2003) sobre los satirógrafos "menores".

2 Fr. 9 Müller en $F H G$ vol. IV, p. 331.

3 Con la lectura $\pi \dot{\alpha} \theta \circ \varsigma$ de los códices.

4 Uso "coro" cuando hablo en general del coro como teatral, en cambio uso "Coro" cuando trato acerca de un coro personaje de un drama específico.

5 Traduzco $\beta \alpha p \beta i \tau \omega \nu$ por "liras", hecho que no refleja la especificidad del instrumento mencionado. Sobre la función del bárbiton en el drama satírico, véase Voelke (2001, pp. 97-104). En general, bárbiton es un instrumento de sonido grave que la iconografía y la literatura asocian a personajes masculinos que juegan roles o son afeminados, como se observa en los vasos llamados anacreónticos del 520 al 450, donde los ejecutantes aparecen con vestimentas femeninas y trazos frigios.

6 Esta es la opinión que nos transmite, por ejemplo, Pausanias 2. 13.6 (=Aesch. T 125 b R).

7 La expresión $\pi \circ \lambda \lambda \dot{\alpha} \delta \omega^{\prime} \xi \xi \varepsilon \tau \iota$ tiene un claro doble sentido: la náyades, que usualmente son perseguidas por los sátiros, los perseguirán a estos atraídas por la maravilla del fuego. A partir de aquí podría estructurarse una serie de metaforizaciones o eufemismos sexuales en el acto de "perseguir" y de "quemarse". A mi criterio es interesante pensar en que la imagen que resulta de las palabras del Coro es la contraria a la que muestra la cratera Viena IV 1011 (pintor Dinos), donde Amímone es acosada por los sátiros.

8 Sobre la identidad del coro satírico, el rol del vestuario en la caracetrización de diversos roles corales y la expectativa del espectador, véase Shaw (2015-2017). En p. 120 y s. Shaw afirma con total claridad que la famosa sentencia de Lissarrague que sostiene que un drama satírico se logra insertando un coro de sátiros en un mito, es una simplificación que no toma en cuenta que son pocos los mitos que se convierten en tramas satíricas, pues no todo mito permite variaciones realizadas por la acción de un grupo de sátiros. Sobre el mito y el drama satírico, véase Melero (1991).

9 Sobre la presencia de los sátiros en el folclore popular griego, véase Edmunds (1994).

10 El espacio pastoral de la obra es bien argumentado por Voelke (2001, p. 39) y Jiménez Justicia (2016, pp. 40-42).

11 En este sentido Jiménez Justicia tiene razón al decir que el tema pastoral que se observa en el Cíclope de Eurípides era común como muestran los títulos de Esquilo Prometeo encendedor del fuego y Glauco y los de Sófocles, Ínaco y Rastreadores. Napolitano (2000, pp. 54-61) analiza ampliamente la adaptación del modelo épico de Odisea a la escena euripidea. Una distancia evidente entre el relato de Odisea y la trama euripidea es la escena de simposio y el $\kappa \tilde{\omega} \mu \circ \varsigma$ que debiera seguir (y que el Cíclope pretende realizar) pero que Sileno y Odiseo impiden. Sin embargo, esta modificación en la trama no es forzada por el Coro, el cual se limita a burlarse del sátiro una vez cegado.

12 Sobre este tipo de cantos populares como componente del drama satírico, véase Seaford (1984, p. 35) y, para este caso concreto del Cíclope, Napolitano (2003, p. 154). Rossi (1971, p. 22) ya señalaba el sutil empleo euripideo de este canto, al remitirlo a un canto rítmico de arenga a los remeros que, ciertamente, hacen un gran esfuerzo físico.

13 Así lo sugiere Seaford (1984, p. 35 n. 34).

14 Dettori (2016, p. 136) retoma la propuesta de Siegmann (1948, p. 113) que se basa en el Fr. 171 R de Sófocles.

15 Chourmouziades (1974, pp. 67-69), citado por Dettori (2016, p. 136).

16 Para una discusión extensa, véase Collinge (1958-1959), Sutton (1974), Seaford, (1984, pp. 4-5) y Seidensticker (1999, pp. 24-25), para quien tiene un rol comparable a Dánao en Suplicantes de Esquilo y a Hécuba en Troyanas de Eurípides.

17 Kousoulini (2015) incluye este canto de Sileno en el conjunto de canciones femeninas populares. Su análisis recoge las características populares y femeninas de estos cantos que concuerdan con el tipo de vida que propone Sileno y con su

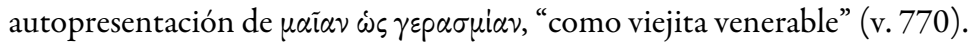


18 Desde esta perspectiva podría proponerse que Eurípides da cuenta de una función necesaria del Coro en el género satírico, entonar cantos líricos populares, y, al mismo tiempo resta toda importancia de la acción coral en la trama.

19 Esto es muy interesante pues Sileno está pidiendo hacerse cargo de la educación de un héroe muy importante para la cultura griega como es Perseo, tal como hubiera hecho, por ejemplo, con Dionisio.

20 No pretendo decir que el curso final de la obra cambie la trama, pues está claro que la norma del género lo prohibía. De hecho, comparto la reconstrucción del final según la cual, cuando el Coro pretendía dar inicio a las bodas entre Dánae y Sileno, reingresaba a la escena Dictis para impedirlo y reconducir a los sátiros a una posición subordinada.

21 Véase Dettori (2016, pp. 186-187) para un análisis de las diferentes atribuciones de estos versos.

22 Véase Dettori (2016, pp. 186-187) para una revisión completa de las posibilidades de asignación propuestas.

23 La compleja situación de Sileno como actor independiente del coro o como su corifeo, es objeto de debate. La hipótesis que propongo se basa en el análisis de Sutton (1974) que lo considera un "tertium quid" con la capacidad de alternar entre ambos roles.

24 La interpretación presentada tiene sus antecedentes en Cantarella (1948, p. 57, citado por Dettori 2016, p. 193) y Werrede Haas (1961, p. 70) quienes, básicamente, entienden que el silencio de Dánae es la "ocasión muda" invocada por el Coro. Dettori (2016), por su parte, sostiene que la ocasión es la interpretación errónea por parte de los sátiros por un “wishful thinking' pittosto che qualcosa a cui Danae abbia positivamente dato adito." (p. 193).

25 Di Marco (1991, pp. 48-49) sostiene con todo acierto que en esta escena la respuesta airada de Dánae y el llanto de Perseo, frente a las palabras de Sileno y la vista del Coro, implica una interrelación entre Coro y personajes como no se registra en tragedia y, de las reacciones antes dichas, podemos deducir que era una escena de fuerte contenido mímico. Concuerdo con el análisis y su afirmación y añado que la mímica es del Coro mientras Sileno habla y canta, por lo que la reacción frente a las palabras y a los gestos presenta al espectador una escena en la que no hay una clara separación entre Sileno (como personaje o corifeo) y el Coro, de manera que el ingreso de Dictis podría no significar un "tercer" actor en la escena.

26 Véase De Santis (2005) sobre la articulación de estos componentes en la construcción de las Erinias como Coro de Euménides.

27 Kamerbeek (1954, p. 110). Para Halleram (1989, p. 268) es un eufemismo de "genitales". Henderson (1991) afirma:

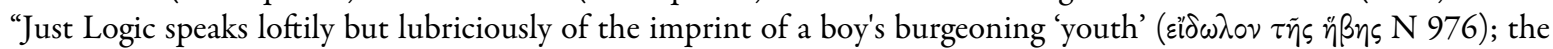

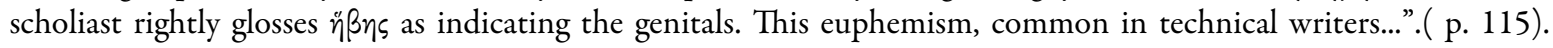
Dettori (2016, p. 204) acepta esta interpretación.

28 Dettori (2016, pp. 179-180). Las relaciones parentales que denota $\kappa \eta \delta \varepsilon \sigma \tau \dot{\eta} \varsigma$ son yerno, suegro, cuñado o primo paterno, según detalla Thompson (1971), por lo que el término incluye un campo amplio de lazos familiares.

29 Un análisis de la partitura métrica y sus implicancias en la interpretación de los versos 786-832 es ampliamente desarrollado por Cerbo (2015, pp. 72-77).

30 Como afirma Cerbo (2015, pp. 104-106) esto constituye una resemantización del discurso lírico completo en el pasaje de la tercera tragedia al drama satírico donde el espectador acondicionaba su oído a la diversa tonalidad de metros usados en la tragedia, ejecutados ahora a la manera briosa y socarrona de los sátiros.

31 En este sentido, la noción de “mediación coral” que utiliza Gagné y Govers Hopman (2013), debe incluir también las frustadas resoluciones que atenten contra la historia o saga base del mýthos en los que el coro satírico, foráneo a estas historias, se ve inserto.

32 Me refiero a la definición de drama satírico de Demetrio de eloc. $169 \tau p \alpha \gamma \omega \delta i \alpha \nu \pi \alpha i \zeta o v \sigma \alpha \nu$ y su efecto emotivo central, $\delta i \dot{\alpha} \chi v \sigma \iota s$. En cuanto al cambio emotivo entre el drama satírico y la trilogía trágica precedente me baso en el análisis de Palmisciano (2008) sobre el Cíclope de Eurípides. 